\title{
SOCIAL AND PSYCHOLOGICAL PROBLEMS OF SURVEYS ON HEALTH AND ILLNESS
}

\author{
JUHN P. KIRSCHT \\ School of Public Health, The University of Michigan
}

\begin{abstract}
Survey methods offer the possibility of obtaining extensive health information on populations, including the identification of people's health status and the nature of their illnesses. The inadequacy of respondent reports concerning ill health conditions, as a substitute for medical diagnoses, has been amply demonstrated. Research has identified many factors that contribute to biased or inadequate reporting. The central problem, however, is a conceptual one. Data collection techniques must fit the nature of the problem. Many health relevant questions pertain to the psychosocial experience of health and illness; survey methods are often appropriate for such questions.
\end{abstract}

WITH the popularity of health surveys, and their promise to provide health professionals with information on the health status of populations, a series of questions have been raised concerning the usefulness of such data [1-4]. This paper will examine the objectives of sample surveys related to health, the difficulties encountered, remedies proposed to deal with shortcomings, and the central conceptual problem of our approach to health and illness.

Survey methods appear to offer a relatively cheap, quick way to obtain large amounts of health-relevant information from any specifiable population. Historically, there appear to be several types of objectives that form the basis for a health survey:

1. Foremost perhaps is the need for basic information on the extent and nature of health problems in a population-we know that many problems are never treated by a physician, that much treatment initiated in response to symptoms is not followed through, and that most medical records are of little value in estimating illness in a group. The rationale behind the National Health Survey referred to the "need for general purpose health information for assessment of national health problems" [5].

2. The administration of health services seems to require knowledge of the people for whom services are to be provided-where are they, what are they like, what they need [6]. With the recent emphasis on planning services and on rational decision making in allocating resources, information concerning health needs is in great demand. While health workers may think they know their communities, the fact is they don't.

3. Better understanding of factors related to health problems requires systematic collec: tion of information. There is no question that social and psychological factors are related to the occurrence and progress of diseases, for example, VD or coronary heart disease. Social research in general and survey research in particular seems necessary to identify conditions that contribute to illness and accidents [7].

4. Finally, we want to know what actions people take in response to health problems. Most behavior relative to illness is voluntary or, at least, socially determined. There are both very imperfect records of recommended health behaviors and astonishingly little information on the popular health culture that determines self-medication and lay referral [8].

Survey research then has been regarded as an appropriate tool to deal with these kinds 
of objectives, whether at a theoretical or highly applied level. Well designed surveys have some powerful advantages, at least in theory [9]: they cover a representative sample of a specified population; respondents are not self-selected; information is available directly from the consumer; wide coverage of subject matter is possible; the information is in standardized form. The major point to be made here is that survey research is better suited to some purposes than to others.

\section{THE TROUBLE WITH HEALTH SURVEYS}

Survey research always presents some problems. The best known of these is dependence on self-report (although there is nothing inherent in a survey that requires responses to questions); succinctly put, it is often said "People don't tell the truth" and that is taken as the rock on which the credibility of a survey founders. A special aspect of that problem is the attempt to assess health status by means of questions. These include open questions asked by an interviewer, symptom lists, disease lists, proxy questions, and so on, but in any particular instance, the objective is a report by the respondent on the occurrence of ill health.

At one time, respondent reports of illness were regarded as an imperfect but valid substitute for a medical report from a physician. The notion was that the individual could tell an investigator what diseases and conditions he suffered from and that this was a very cheap alternative to a physical examination and set of diagnostic procedures. Perhaps no one ever believed that self-reports were interchangeable with medical procedures for detecting illness, but the question of validity of the reports evoked an awesome outpouring of research. The initial question concerned to what extent do respondents' answers to items concerning illness correspond to medically defined diagnoses. As work in this area evolved, the questions asked became increasingly sophisticated. Basically, however, the answer is that respondents in surveys are poor substitutes for physicians (or vice versa).

When medical records of various types are compared with household survey data, the extent of non-correspondence is impressive. There are all sorts of variations in the details of comparison; for example, Sanders [10] compared rates of chronic conditions derived from NHS data with diagnoses in clinical examinations; Woolsey [11] discussed survey based conditions in relation to the diseases and conditions recorded on a standardized Physician Visit Report.

1. The Health Insurance Plan of Greater New York sought to relate medical record data on chronic illness of patients who had received care under the HIP program to data derived from National Health Survey interviews [12]. In the medical record, tentative and final diagnoses were available; records for the past year were used, corresponding to the time period covered by interview questions. Nearly 5000 chronic conditions were included in the study.

\begin{tabular}{lc}
\hline Condition & $\%$ Match \\
\hline Heart conditions & $44 \cdot 5$ \\
High blood pressure & $39 \cdot 0$ \\
Diabetes & $61 \cdot 7$ \\
Arthritis and rheumatism & $22 \cdot 3$ \\
Hernia & $54 \cdot 4$ \\
\hline All & $20 \cdot 0$ \\
\hline
\end{tabular}


From this study, the researchers drew the following conclusions:

"(the results) suggest strongly that survey information does not conform even moderately well to the universe of conditions inferred from physician reporting. . . Furthermore, the fact that a physician has recorded a diagnosis of a disease usually thought of as serious, or containing all the elements of chronicity (e.g., diabetes or heart disease) by no means gives assurance that the condition will be identified by the respondent in an interview." [12, page 29].

Sanders, in an article titled "Have morbidity surveys been over sold?" [13] reports some dramatic instances of non-correspondence between surveys and medical reports. For example, in one study, clinical examinations on a sample of Health Survey respondents utilized the same checklist of 32 discases as that used in the survey. About one third of the responses corresponded; the largest group of responses were "false negatives," i.e., "yes" to a physician and "no" to the interviewer. In another study, there was an attempt to validate patients" statements concerning whether they were circumcized. Over 34 per cent of the reports did not match examination findings [14].

Sanders had noted previously that there was marked variation among interviewers randomly assigned to households in eliciting information on illness and health conditions - variation beyond that reasonably attributable to sampling error [15]. Further, responses concerning ill health depend on the way questions are asked. Question formats range from very open items to closed checklists of symptoms and diseases. In general, the more specific and detailed the questions, the more disease is found. Most illness is uncovered with a diary method where short intervals of time are used [16].

3. That the situation has not changed is illustrated by a recent review [17] which concludes that under-report is the characteristic problem in surveys. Even reports of hospitalization vield a surprising degree of inaccuracy. While much of the non-correspondence may be explainable, its existence gives one pause.

4. A chronic problem is that of who responds. Typically, health surveys use one respondent per household, for various reasons, including convenience [18]. For example, in an influenza survey, husbands and wives reported more illness for themselves than for their spouses so that the spouse was always in better health than the respondent [19]. The health of the nation improves markedly when proxy respondents are used; differences are even more noticeable when the respondent for a family is Uncle Joe.

5. While the match between responses to a question concerning illness and a medically defined disease category may be poor, general assessment of people's health status should correspond better as between respondent and physician. Unfortunately, even here, the match may be poor. Feldman, in his review of health surveys, concludes that clinical assessment of general health is only slightly correlated with survey information [20]. A recent report by Kisch et al. [21] finds reasonably good relationship between an overall medical evaluation and a measure developed by combining answers to questions concerning taking medicine, acute conditions and chronic conditions. Although no detailed match is attempted, there is still a fair amount of "under-report" by the patients. Even if a general assessment of health is reasonably accurate, there is the dilemma of loss of detail in information $v s$. use of potentially reactive measures.

6. Health related actions have been the subject of numerous studies concerning response validity. Simmons and Bryant [22], reviewing National Health Survey research on reporting of hospitalization, concluded that data on hospital episodes "can be collected through 
household interviews with a degree of accuracy satisfactory for many purposes" $[22, \mathrm{p}$. 1647]. That must be qualified, however, in the light of details presented by Cannell and others [23]; accuracy was found to depend on several factors, including recency of the episode, duration of stay, and diagnostic category. In addition, a comparison of three methods for obtaining hospitalization reports [24] demonstrated that a combined interview and self-administered questionnaire yielded greater accuracy, especially for less educated and proxy respondents. The results were attributed to increased motivation on the part of respondents.

Validity of reports on use of outpatient facilities was studied by Solon and others [25]. As in the research on hospitalization, under-reporting was noted, with validation against hospital records. About three-fourths of the respondents accurately reported the specific clinics used. Record checks were also used by Hochstim [26] in a comparison of a face-toface interview, mail questionnaire, and telephone interview; of reported cervical tests for cancer taken by women, 81-87 per cent could be verified, with greater accuracy yielded by the mail questionnaire. Hochstim noted, however, that many women were apparently not aware that they had received the test in the course of a pelvic examination.

As indicated in the review by Cannell and Kahn [27], the accuracy of behavior reported in surveys shows considerable variation. Generally, the results of validity checks can be explained in terms of the type of information sought, especially the degree of threat to the respondent, and the demands for information retrieval put on respondents.

The conclusion seems to be that survey responses are poor substitutes for physician diagnosed conditions or even general evaluations of health; reports on the use of health services and other medically relevant actions appear to fare better, but their accuracy depends on the type of information and the manner in which it is sought. Note the assumption here, in relation to diagnoses, that the physicians" assessment is the "true" one, or, put more broadly, that current medical conceptualization of illness is valid. I pass over the data that seems to indicate substantial unreliability among physicians in looking at the same patient and problems inherent in attempts to examine a cross-section sample [28].

\section{REMEDIES AND OBJECTIVES}

From a social and psychological point of view, what happens in health surveys? A great deal of work has been done with respect to factors that affect or "bias" reports of health and illness; the impetus was provided both by problems of response validity and by interest in understanding the psychosocial bases of responding to questions [29]. Rather than reviewing the research, an outline of factors related to response tendencies will serve to illustrate the problems:

Cognitive factors-does the respondent have the information in usable form?

Awareness of symptoms, definition of the problem, memory for past events (recency, frequency), terminology for illness, specificity of questions, (for proxy response) awareness of others' behavior, role.

Motivational factors-is the respondent willing to report the information?

Threats to respondent's social image, perceived consequences of reporting, involvement in role of respondent, appropriateness of interaction with investigator.

Consideration of these factors yields a better understanding of what happens when healthrelevant information is collected directly from a respondent [30]. Incidentally, one basis 
for medical diagnosis comes from question and answer between the professional and the patient. The same problems are there in terms of what data are obtained. Many physicians and nurses are poor interviewers and talk to patients in ways that guarantee biased reports; further, educational efforts by the professional frequently ignore the realities of what patients can or can't learn and what they may or may not put into practice.

The knowledge we now possess of response biases suggests a number of remedies: training interviewers, careful attention to question wording, potential threats to the respondent, preparation and reward factors in data collection process and so on. These are, however, essentially improvements in the existing machinery. Such improvements, while absolutely necessary for better surveys, don't deal with some basic problems.

The primary difficulty is a conceptual one. What is the research problem under study? Many surveys appear never to have asked that question. Rather, the collection of information is frequently initiated with a hazy professional medical conception of health and illness, quickly translated into an operational form that results in trying to squeeze people to fit the concepts. For example, the typical check list of diseases probably contains at least 50 per cent terms that aren't known by half of the population. For example, one list may ask about "eczema", another about "skin trouble". The lists are mixtures of diagnostic categories of varying specificity, symptoms, causal statements, and lay descriptions of functions. We make distinctions between preventive health measures and those that detect the presence of a particular condition. Such a distinction simply doesn't exist for many people; for them, a checkup by a physician has the same efficacy against disease as a tetanus innoculation [31].

After some false starts, the National Health Survey recognized that survey information is not a substitute medical procedure and came to a predominantly social conception of ill health:

"Morbidity is basically a departure from a state of physical or mental well-being, resulting from disease or injury, of which the affected individual is aware . . the concept of a morbidity condition is usually further limited by specifying that it includes only conditions as a result of which the person has taken one or more of various actions. Such actions might be the restricting of usual activities, including going to bed, the seeking of medical advice, or the taking of medicine." [32]

Actually, this is only part way toward a subjective definition of health, since the National Health Survey still reports data as if medical definitions are used. Other reports, such as those on subjectively defined disability resulting in the sick role, are more clearly appropriate to the type of information collected.

The problem is that of defining conceptually what is to be studied, then selecting operational measures that are appropriate. With respect to health, surveys are potentially useful for some problems. A few of these will be outlined.

The extent and distribution of some specific conditions can probably be accurately determined by survey methods, provided that sufficient care is taken to define a set of symptoms or a diagnosis for the respondent. People can tell an investigator what their complaints are but it is clear that this must be treated as illness behavior [33] and not as a clinical examination. The Baltimore health survey goes in this direction [34]. The existence of a particular complaint is quite different from trying to obtain a total picture of medically defined health status.

Similarly, one can examine the environment for specific conditions, such as accumulations 
of trash, dilapidated housing, evidence of rats and vermin, lead paint inside houses, household medicines and poisons. The existence of these conditions and their distributions may be of particular importance to public health. An observational survey in this instance is an appropriate tool, provided the observers are well trained. Part of the ECHO survey procedure in Michigan communities involves observation and ratings of households [35].

The many studies of public information, attitudes, and behavior relative to health were reviewed by Suchman [36], with the comment that most are deficient in design or execution: inadequate samples, poorly constructed questionnaires, unskilled interviewing, and inadequate analyses. The same considerations apply to many surveys designed to obtain public evaluation of health services.

Well-established and sophisticated methodology now exists for surveys of attitudes, beliefs, and knowledge. While much of the technique for conducting a well done survey is still an art, there is an extensive literature of careful methodological research; the major components of good survey practice can be specified. In the areas of belief and attitude, however, problems of response validity have never been well resolved. The crux of the matter is whether questions elicit actual attitudes or beliefs or intentions to take actions. What is the criterion? While known suspect practices can be avoided, including the use of single items to assess complex beliefs, lack of pretesting on questions, ambiguous wording, unreal hypothetical referents, and so on, researchers must explore the construct validity of their items and utilize multiple assessments of health-related phenomena. To do so implies development and verification of theoretical relationships, especially connections among beliefs, information, motives, and behaviors. That is the only route to testing the validity of belief-type assessments.

For purposes of evaluation, many programs can be stated as a set of hypotheses centered around a particular outcome (for example, that 80 per cent of children aged 12 years and under be immune to rubella). To get there, a series of conditions must be met-these are sub-objectives of the program [37]. These conditions need to be stated-such as, in order for people to obtain the vaccine, they must know the place and time where it is available. Many of our programs have knowledge and motivational sub-objectives, or depend on the existence of necessary transportation and timing arrangements. Serious evaluation must determine whether the sub-objectives are met in order to focus on places where programs are weak or fail. Surveys are possible as modes for collecting such information-do people know, are they willing, what are the social and economic and physical barriers?

Among other things, people can tell us about their own health, illness, and sick role bchavior. Some examples of personal health beliefs and observations:

- whether a given set of symptoms were noticed and what did or might happen as a result;

- what definitional behavior respondents went through when a sign about health status was observed; what categories are used, who is consulted, what is noticed in other people, what is appropriate illness behavior;

-the nature of the sick role, who is entitled to employ it, when, how often, the costs, the benefits, and what is the individual's disposition to enter the role;

- what paths of action are seen as available and cffective with respect to health, including self-medication, lay referral, as well as the professional medical system.

Question and answer methods of gaining information face a fundamental language problem-whether in surveys or in medical history taking. Language is not completely shared in any cross section of the population and no single questionnaire can ever provide items that are understood in the same way by all respondents. From a medical point of view, 
a person has not "had" a disease or condition until it has been diagnosed by a physician. People can, however, have symptoms but even these are dependent on a frame of reference and set of cognitive categories. The point is that questions about health and illness have some inherent ambiguity; recognition of this is necessary in formulating items and deciding upon means for data collection.

What problems are being addressed here? There appears to be a gap, often of serious proportions, between the professional health worker and the public. Both sides might profitably be educated as to the others' definitions of situations, purposes, and practices. When a health worker tries to get people to stop drinking polluted water so that they will no longer suffer chronic diarrhea, he may tell them that they will then no longer be sick; the people, however, may insist that they aren't sick and that what the professional sees as illness is simply a part of life, the normal state of affairs.

What are "health problems"? On one hand, medical definitions may bear little relationship to things regarded as health issues by the community. It may be that the crucial issues for a group of people revolve around the need for getting children across a street safely, or having a place for them to play, or psychological support for despairing old people. When a health worker shows up to promote pap tests, there may well be little interest. On the other hand, attempts to find out "health issues" may fail if not properly defined and probed. Knutson [38] tells the story of interviewers in a community asking people what their "health problems" were, with little response. When, however, they changed tactics and inquired about things wrong with the neighborhood and personal difficulties, all sorts of health problems came out. I am suggesting that survey research may be useful in finding out people's problems and that the information may help public health respond to public issues.

Finally, there is the troublesome question of health needs, or more properly, when is a need there? We may ask whether there is some ultimate validity to a professional medical determination of health. And in the sense of formal diagnosis of physical conditions and prognosis for that condition, medical science represents the best conjecture we have at a given moment in time. In that sense there is no substitute for a physician and laboratory. But there is also an ultimate validity to health beliefs, to symptoms, to the popular health culture.

Again we come back to the purposes of gathering information and the procedures that should flow from those purposes. Certain aspects of needs can be most easily inferred from subjective responses of people and the survey approach serves a useful purpose for such information.

In summary, household morbidity surveys can never tell us more than what the respondents believe to be the case. What the correlation is between a person's beliefs about himself and a physician's beliefs about him is a matter to be settled by empirical research and such research done to date does not support the view that the patient's views of his health and the physician's views are highly related. Thus, an inherent weakness in the survey as an index of health is that respondents cannot move outside their own experiences and beliefs. However, that weakness can be made a virtue if the focus of the survey is on the very things that only the respondent can tell us-his complaints, the extent to which he has knowledge and motives that we wish him to have, the way he views various physiological states, his health practices, his lay referral systems, his views about various kinds of practitioners. Such information can provide a sound basis for program evaluation and planning but only when we are willing to admit that the client's views have an inherent validity despite their non-correspondence with professional views. 


\section{REFERENCES}

1. Feldman, J. The household interview survey as a technique for the collection of morbidity data. J. Chron. Dis. 11, 535-557, 1960.

2. SANDERS, B. Have morbidity surveys been oversold? Am. J. Publ. Hith 52, 1648-1659, 1962.

3. Haberman, Paul W. The reliability and validity of the data. In Poverty and Health (edited by Kosa, J., AntonovsKy, A. and Zola, I.). Harvard University Press, Cambridge, 1969.

4. Mechanic, D. and Newton, M. Some problems in the analysis of morbidity data. J. Chron Dis. 18, 569-580, 1965.

5. National Center for Health Statistics, Health survey procedure: Concepts, questionnaire development, and definitions in the National Health Survey. Series 1, No. 2, May, 1964.

6. Tayback, M. and Frazier, T. Continuous health surveys: A necessity for health administration. Publ. HIth. Rep. 77, 763-771, 1962.

7. KasL, S. and CoBb, S. Health behavior, illness behavior, and sick role behavior. Arch. Emiron. Hith 12, 246-266 (Pt. 1) \& 531-541 (Pt. 2), 1966.

8. Polgar, S. Health and human behavior: Areas of interest common to the social and medical sciences. Current Anthrop. 3, 159-205, 1962.

9. Moser, C. Survey methods in Social Investigation. Humanities Press, New York, 1958.

10. SANDERS, B., op. cit.

11. Woolsey, T., Lawrence, P. and Balamuth, E. An evaluation of chronic disease prevalence data from the health interview survey. Amer. J. Publ. Hith 52, 1631-1637, 1962.

12. National Center for Health Statistics, Health interview responses compared with medical records, Series 2, No. 7, p. 29, July, 1965.

13. SANDERS, B., op. cit.

14. Lilienfeld, A. and Graham, S. Validity of determining circumcision status by questionnaire as related to epidemiological studies of cancer of the cervix. J. Nat. Cancer Inst. 21, 713-720, 1958.

15. Sanders, B. Methodological implications of the morbidity survey. In $A$ health study of Kit Carson County, Colorado. PHS Publication No. 844, pp. 31-71, 1962.

16. Wilcox, K. Comparison of three methods for the collection of morbidity data by household survey. Dr. P.H. dissertation, Univ. of Michigan, Sch. of Public Health, 1963.

17. Haberman, P., op. cit.

18. National Center for Health Statistics, Health survey procedure.

19. Public Health Service, The impact of Asian influenza on community life. PHS Publication No. 766, 1960.

20. Feldman, J., op. cit.

21. Kisch, A., Kovner, J., Harris, L. and Kline, G. A new proxy measure for health status. Filth Serv. Res. 4, 223-230, 1969.

22. Simmons, W. and BRyant, E. An evaluation of hospitalization data from the Health Interview Survey. Amer. J. Publ. Hlth 52, 1638-1647, 1962.

23. National Center for Health Statistics, Reporting on hospitalization in the health interview survey. Series 2, No. 6, July, 1965.

24. National Center for Health Statistics, Comparison of hospitalization reporting on three survey procedures. Series 2, No. 8, July, 1965.

25. Solon, J. et al. Patterns of medical care: validity of interview information on use of hospital clinics. J. Hith \& Hum. Behav. 3, 21-29, 1962.

26. Hochstim, J. Evaluation of three approaches to information collection in an epidemiologic study of cervical cytology. Human Population Laboratory, Calif. Dept. Public Health, May, 1963.

27. CANNell, C. and KAHN, R. Interviewing. In The Handbook of Social Psychology (edited by LrND7Fy, G. and Aronson, E.), Vol. 2 (2nd Edn.) Addison-Wesley, Reading, Mass., 1968.

28. HABERMAN, P., op. cit.

29. KAHN, R. and CANNELL, C. The dynamics of interviewing. Wiley, New York, 1957.

30. National Center for Health Statistics, Reporting on hospitalization in the health intervicw survey. Series 2 , No. 6, July, 1965.

31. Kirscht, J., Haefner, D., Kegeles, S., and Rosenstock, I. A national study of health beliefs. $J$. Hlth. \& Hum. Behav. 7, 248-254, 1966.

32. National Center for Health Statistics, Health survey procedure.

33. KASL, S. and COBB, S., op. cit.

34. TAYBack, M. and Frazier, T., op. cit.

35. LEWIS, R. Michigan health survey: A brief report of operational status. Michigan Dept. of Public Health, January, 1970 (mimeo).

36. Suchman, E. The survey method applied to public health and medicine. In Survey Research in the Social Sciences (edited by GLoCK, C.). Russell Sage, New York, 1967.

37. Deniston, O., Rosenstock, I. and Getting, V. Evaluation of program effectiveness. Pub. Hith Rep. 83, 323-335, 1968.

38. KNUTSON, A. The individual, society, \& health behavior. Russell Sage Foundation, New York, 1965. 